\title{
DIGITALIZED MANAGEMENT OF EDUCATION AND SMART SCHOOL LIBRARIES
}

\section{Hung Ngoc Le ${ }^{1,+}$, Phuong Thi Bui'}

\section{Article History}

Received: December 12, 2019

Accepted: February 02, 2020

Published: March 30, 2020

\section{Keywords}

Digital library, smart school, educational management, digitalization

\author{
${ }^{1}$ VNU University of Education, Vietnam National University; \\ ${ }^{2}$ Hanoi University of Public Health, Vietnam \\ ${ }^{+}$Corresponding author • Email: lengochung.vnu@gmail.com
}

\begin{abstract}
Case studies of changes in the status and roles of smart school libraries point out that the world has entered the "digital era" with digital libraries, smart libraries, smart schools and smart classrooms featured with research and development, Internet-based innovation of modern communication technology. In Vietnam, educational management in general and university governance in particular are undergoing a radical and comprehensive renovation in which libraries are digitalized to become smart libraries to better meet the needs of learners, instructors, managers and people interested in scientific research and training of high quality human resources.
\end{abstract}

\section{INTRODUCTION}

In a modern society, knowledge becomes an advantage, a kind of special power referred to as 'an invisible power' (Peter Drucker, 1995), "a soft power", "smart power" (Joseph S. Nye, Jr, 2016). In education, knowledge in the form of books is the second teacher after the first teacher who directly teaches students (Le Ngoc Hung, 2019). Under the impact of the fourth industrial revolution 4.0, knowledge is digitalized. This kind of digital knowledge becomes "a digital natural resource", "digital capital" with the force of the power interpreting the world, becoming the worldchanging force in a fast and unpredictable manner. In such circumstance, the issue raised is that what would educational management be digitalised and related to smart school libraries.

The main point of this paper is digital knowledge makes an essential change in the objectives, content, form and method of educational management in general and school management in particular. However, in reality, education management is mainly studied and developed in managerial theoretical approach based on non-digital knowledge of the last century. The radical and comprehensive renovation in education requires educational management to be the first in applying the advancements of digitalizing scientific knowledge to ensure the improvement of education quality (Le Ngoc Hung, 2019). In this situation, it is urgent to study digitalized knowledge mainly reflected in digital libraries of schools and its impact on educational management.

\section{LITERATURE REVIEW}

\subsection{Smart school and smart school library}

A smart school is an educational, learning and teaching institution with autonomy, activeness, self-awareness, , and intelligence, with the use of modern communication technology to develop learners' smart abilities (Le Ngoc Hung, 2019a; Le Ngoc Hung, 2019b; Omidinia, S. et al., 2012; Zhu, Zhi-Ting et al., 2016). A typical feature of a smart school is a smart library to ensure data resources for teaching and learning. Educational resources are all data resources that are produced, saved, accessed, publicized and used through digital technology in learning, teaching, researching and management and other educational activities. The management of a smart school is to administrate smart teaching targeting at smart learning activities to develop smart abilities, qualification and skills of the learners. Smart learning is active, voluntary, adaptive, creative learning using modern communication. A visible typical feature of a smart school is that modern communication means are connected to the Internet and digitalized technologies are used commonly in all divisions of the school including smart libraries and management. Probably owing to the increasing importance of digital technology, the terms "digitalized" and "digital" can be used instead of the term "smart" except for clearly stated cases (Omidinia, S. et al., 2012; Zhu, Zhi-Ting et al., 2016; European Commission/ EACEA/Eurydice, 2019; Balyer, A., \& Öz, Ö., 2018; Bond, B. et al., 2018; Cerna, L., 2014 and OECD, 2016).

\subsection{Digitalization, digital education and digitalized management of education}

Digitalization is a process of digital transformation characterized by the use of digital technology and digital information in human activities (European Commission/EACEA/Eurydice, 2019; Balyer, A., \& Öz, Ö., 2018; Bond, 
B. et al., 2018; Cerna, L., 2014 and OECD, 2016). Digital education is education using digital technology in order to formulate and develop the digital knowledge and competence of learners. Digital competence is ability to understand, access and use digital technology in learning, working, living and participating in the social life. Some elements that have a decisive role in the success of digital education is to renovate the management from a traditional approach to a digital one and this is the digitalization of education management.

Digitalized management of education is one of tendencies of digital transformation in education in order to adapt to the requirement of digital economy, the fourth industrial revolution and especially the requirement of social renovation in the twenty-first century (OECD, 2016). The transition of traditional education management to digitalized education management requires many factors including digitalization technology and other resources. With the bottom-up approach, digitalized management of education needs the understanding and supports from both the learners and teachers. Digitalization technology needs to be used in the learning and teaching process, therefore the teachers must have digital knowledge and skills to attract the learners in the process of studying, using and developing digital knowledge and skills. According to the bottom-down approach, the digitalized education management requires government's investment and the support from relevant stakeholders. Within the school, digitalized education management depends on the school's policy and plan in the training and investment for the teaching staff, improving knowledge and skills in using digital knowledge in teaching and the entire administration system of the smart school.

Digitalized education is reflected clearly in the digitalization of the teaching methodology of teachers, the learning methods of learners and educational resources. The library of the school becomes digital and smart, thus contributing to the formation of the smart school.

Some international comparative studies indicate that the use of Internet-connected communication devices such as computers, laptops, smart telephones is now increasing even though it is not equal in education around the world. In the industrialized countries on average, $96 \%$ pupils beyond the age of 15 have computers at home and $43 \%$ have more than 3 computers and only $4 \%$ do not have computers at home (OECD, 2016). Out of 64 countries participating in PISA in 2012, Vietnam was ranked second from the bottom with $61 \%$ of the pupils of age 15 and beyond living in families without a computer. Indonesia had the highest rate of $74 \%$ of pupils not having a home computer. In 2012 , 93\% of pupils in OECD countries reported that their families had Internet-connected computers while in Indonesia, Thailand, Peru, Mexico and Vietnam only a half of all households had Internet-connected computers. On average, the pupils over the age of 15 in the OECD countries spent 2.29 hours using the Internet at school every day and 0.64 hour a day at home (OECD, 2016).

In short, theoretical and empirical studies indicate digitalized management of education is connected to societal change and educational change in particular. Educational change is a transformation or alteration with or without purpose to create a difference in education and therefore connected to the educational differentiation. The education innovation is understood as a process to create conscious and structural change. The innovation is creating and improving ideas, knowledge and practice or bringing about new useful things. One of the instruments, means and skills necessary to innovate is the modern communication technology with digitalized information. Digitalized educational management, therefore, needs to be examined in relation with the formulation of a smart school library at the level of the educational institution and innovation of education environment at the level of educational policy (Cerna, L., 2014; OECD, 2016; Le Ngoc Hung \& Bui Thi Phuong, 2019; Borgman, C.L., 1999).

\section{METHODS AND RESULTS}

\subsection{Methods}

Regarding the research method, this paper uses a non-experiment method with review of related literature. The paper applies generally systematical theoretical approach to analyze the co-relation between the digital knowledge and changes in education management in the context of the renovation of the country, global integration and revolution 4.0 (Le Ngoc Hung, 2019a; Le Ngoc Hung, 2019b; Vietnam National University Hanoi - The Information - Library Center, 2018). Le Ngoc Hung \& Bui Thi Phuong, 2019 and Le Ngoc Hung, 2015). At the same time, the paper also uses a case-study methodology of the smart school library, namely university libraries (Vietnam National University Hanoi - The Information - Library Center, 2018) and reviewing studies in order to clarify a research issue raised for digital education management (Le Ngoc Hung - Bui Thi Phuong, 2019).

\subsection{Research results}

\subsubsection{The concept of digital knowledge and digital library, smart library}


Digital knowledge represents the ability to know, use and develop digital devices and techniques to search for, process, analyze, use, share and develop information and knowledge. Digital knowledge forms a part of the process of digitalizing knowledge. In digitalized educational management, digital knowledge is a part of the subject and means to manage.

Digitalized knowledge represents the knowledge digitalized through digital techniques and devices in order to save, transfer, access, process, analyze, distribute, publicize and use the information, knowledge on modern mass media connected through the Internet. In the world, 2000 is considered the opening year of the digitalized knowledge era with the event where more than a half of the world information has been digitalized to be saved, processed, accessed, publicized and used through Internet-connected means. In Vietnam, in 2017, the project "Developing the digitalized Vietnamese knowledge system" based on Decision 677/2017/QD-TTg officially started with four objectives: (1) Restoring, publishing the knowledge in different areas, especially in education; (2) Creating favorable environment for all people to exploit and enrich digitalized knowledge resources; (3) Inspiring and expanding a love of scientific and technology research, enriching and distributing the knowledge; and (4) Developing the digital content industry, orienting the use of knowledge by users in the Internet environment.

Digital library, smart library. Among a number of definitions of digital library, one made by Borgman $(1999,2000)$ might be the most relevant to the development of library and educational management renovation in the direction of digitalization. Borgman considers a digital library a complex of electronic information sources combined with technical abilities to create, search for and use digital information or digital knowledge. The digital library is formulated, compiled and organized by and for the community of the digital information users (Borgman, 1999). This is a special kind of definition as other definitions of the digital library emphasise too much on the application of technology, techniques of information digitalization and services. This definition emphasizes a critical objective of a digital library, smart library, i.e. to meet the demand for information of the people and community. The digital library serves as a typical component of a smart school. The digital library plays the role of organizing and managing information and knowledge including Big Data and Meta Data to serve educational managers, teachers, scientists, learners and other stakeholders.

\subsubsection{Two theoretical approaches to smart school libraries}

According to the general theoretical approach, smart school library is one of the units forming the whole university education system continuously interacting with the surrounding environment (Le Ngoc Hung, 2015). As a sub-system the library interacts directly and indirectly through the school with the surrounding environment including other libraries outside the school and economic, political, cultural, legal institutions and organizations, especially other educational units. At the same time, as a sub-system, a digital library needs to interact, cooperate with other units, parts, sub-systems of the school to perform the information, media, education and teaching functions and roles to ensure the whole system effectively work in a competitive environment. The principles of the theory of the fourth-generation system - a super knowledge system typical of a knowledge social system indicates that if a library does not fulfill its function and role for the whole education system, there must certainly be another subsystem or another part to do it. Therefore, in a digitalized smart society, a school library will well be a digital library, a smart one, contributing to the formation and development of a smart school.

According to the modern theoretical scientific approach to education management, school libraries, especially university libraries, have a new role of encouraging media, academic/ scholarly communication reflected in the direct assistance to teachers in introducing, sharing, publicizing and discussing scientific works among domestic and international scholar communities. The academic communication requires multi-dimensional social interactions around an axis consisting of library staffs accessing scholar activities and teachers accessing library activities. A smart digital library with three components namely technology, data and people is considered a future library of a school in general and of a university in particular. For a digital library, the library of a smart school, "people" are not simply "readers and information users" but also teachers, learners, researchers, educational leaders, managers, and administrators (Nguyen Huu Gioi, 2018). In a smart school, a digital library has the role of organization, creation and promotion of the information using to formulate new necessary knowledge, skills, abilities and qualifications of the learners. The digital library has the status and role of a "virtual teacher", "virtual class" and even a "virtual school" together with "actual teacher", "actual class" and "actual school" to teach, instruct and support the development of necessary professional scientific knowledge, qualifications and abilities of the learners and other stakeholders. In particular, the library also helps with encouraging the development of creativity, renovation and entrepreneurship among the learners, teachers, educational leaders, manager and administrators and other concerned people. 


\subsubsection{The tendency of developing school digital libraries and the issues in question}

Digital libraries is claimed to develop in five directions as follows: (i) Diversifying rich and complicated information demand. (ii) Synthesizing libraries with the organization of information and library services. (iii) Modernizing equipment to save big data. (iv) Programing softwares for processing and exploiting information. (v) Creating digital information resources (Le Manh Ha \& Tran Hong Nhien, 2018). However, these are "it-self and for it" development directions of a library, that is, without smart education management, a digitalized library may not bring any benefits for education in general and schools in particular.

A digital library provides five types of services, such as supplying documentation, publishing information, exchanging information, training library information users and providing other services like accessing, assisting learning and research services. The names of these services are similar to those of traditional library services but the way of serving are radically changed thanks to the digitalization and increasingly advanced technology. It is noteworthy that due to the impact of a "commercialization" approach, the assessment of digital library quality gives more importance to the satisfaction of library service users. However, one needs to know that a digitalized library of a school has the function of contributing to the implementation of the schools' missions and objectives. That is why the satisfaction with digital library activity quality is just an intermediate criterion to evaluate the education quality of a school. In other words, it is advisable for a digital library to develop the information and knowledge service to assist three typical types of activities of an educational institution, especially a university, namely scientific research, teaching and learning.

In reality, smart university governance actively researches on and applies modern communication media in a digital and smart library. For example, RFID (Radio Frequency Identification) technology has been applied more and more in circulating, controlling and inventory activities of documentation in libraries since 2000 (Vu Thi Kim Anh - Pham Thanh Quang, 2018). The RFID allows computers to recognize documents chip-tagged through the system of radio so that one can supervise, manage and save every document separately when it is transmitted among different physical positions. One of benefits of RFID application is to assist in the building up a system of 24-hour-book returning that can satisfy the need of readers in returning book at any time within a day. However, the application of RFID needs to be administrated in a way so that it can answer questions such as how many readers to borrow books or how many borrowed book RFID can help to increase and how many demand for $24 \mathrm{~h}$ borrowing and returning books within a day. When it comes to the role of a digital library in digitalized education management, a similar question can be raised concerning other benefits of the application of RFID in serving readers, leaners, teachers and researchers. In reality, one library states that after five years, 37,000 reference books are FRID chip-tagged (accounting for 8\% of the total of 450,000 books of the Information-library Center). The Division of General Information Service of this library gains 366,575 circulations, on average 10 circulations borrowing and returning per one book; every day there are 200 circulations of borrowing and returning RFID-tagged books. The problem is that how the application of university education in general and the learning or researching improve the quality of university education in general and of the particular university. Some smart location technologies have been studied and applied to understand the preferences of readers, but this may raise a problem relating to users' privacy in information accessing.

The terminology "Semantic Web" (SW, Web) used by Berners-Lee (2001) to talk about database Web directly and indirectly processed by machine (Berners-Lee, T. et al., 2001). The SW is a development direction of the present Web to ensure that computers can read, understand and use the database in the Web. Researchers point out six areas where SW is applied. They are knowledge management, information seeking, advertisement, E-commerce, social networking and especially digital library (Berners-Lee, T. et al., 2001). However, a question of the SW application in a digital library of a smart school is to pay special attention to the services for teachers, learners and researchers as well as education leaders and managers.

The Book worm is one of the digital library applies to assist readers in accessing and exploiting data sources conveniently at any time, in any place. At the same time, this software assists library in administrating and sharing digital resources and connecting libraries together (Tran Thi Thanh Nga \& Tran Thi Anh Van, 2018). However, university governance needs to pay attention to some emerging issues that may prevent technology applications to support education books from reaching desirable targets. An example may be the issue of cheating when it is too easy for learners to copy documents to share among themselves when they do exercises and read digitalized textbooks and exercise books. Some other issues may be building up learning softwares to help teachers and students, especially the technology of summarizing book contents which may formulate their habit of being lazy to read books. 
The optimal tendency is the research and application of AI (Artificial Intelligence) in the development of digital libraries of smart schools. AI may help to develop: (i) a system of expertise connecting information users to libraries and database; (ii) Natural Language Processing (NLP) for information retrieval - IR, information extraction, question and answer - Q\&A, summary, on-line translating; (iii) pattern recognition; (iv) Robotics with robot librarians and robot books) (Kieu Thuy Nga \& Le Duc Thang, 2018). However, an emerging problem is that the way of presentation and introduction of AI technology is often narrowed in internal activities of digital library without direct connection to study, teaching and research in a university. That is why digitalized education management should concentrate on researching and using $\mathrm{AI}$ in all activities of a university, for example, in the development of learning materials for every class and subject to develop a smart school.

Web scale discovery services (WSD) are modern library services that are able to help in seeking for, exploiting intersector, cross-sector, specialized information to meet the demand of the information users. The problem raised for digitalized education management is how to make these services contribute to the realization of integrated teaching targets in general education, multi-sector, multi-area, cross-sector training in university education (Dang Thanh Son, 2018).

The development and implementation of integrated education programs (in short STEM) and STEAM may suggest a number of thoughts about including university education and post-graduate education programs in university libraries. STEM is the abbreviation of Science, Technology, Engineering, Math and STEAM stands for Science, Technology, Engineering, Art, Math. A digital library has the advantage of formulating an education space relevant to implement these two educational programs. However, educational management needs to develop educational programs to cover social and humanity scientific areas to meet the requirement of human development. The embedded librarianship development tendency has been formed through active participation of librarians in the activities of teachers, learners and researchers to understand their needs and meet them.

The digital library has been developing in the direction of building up and using Big Data, Meta Data to serve information users. However, an issue here is to concretize the user - a teacher, learner and researcher, education leader and manager as well as supporter and other related people in a university. The digitalized educational management raises an issue of orienting the development of digital libraries using Big Data, Meta Data to make a contribution to the formulation of smart abilities, qualifications and creativity of leaners, teachers and researchers. Similarly, a library of a smart school does not simply contribute to the development of Vietnamese digitalised knowledge but also uses it to serve education, training, research and technology.

From the digitalized education management point of view, it is necessary to highly appreciate the development of control applications and services for censoring the duplication of learning, teaching and researching materials. A typical example is a Document Improvement Tool (DoIT), the on-line spelling and plagiarism checking system (Vo Dinh Hieu \& Le Ba Lam, 2018). The application of this tool is to protect learners and teachers from intellectual property violations and assist in training honesty, seriousness, responsibility in education and scientific research.

It is noteworthy that a "classic", traditional approach to university education management in Vietnam often topdown prioritize from (i) education, (ii) scientific research and (iii) serving the community where education accounts for over 70-80\% of the total time amount. A smart digitalized approach prioritizes (i) scientific research, (ii) serving the community and (iii) education where the portion of the scientific research is about $80 \%$. That is because both education and community service rely on science and technology (Le Ngoc Hung, 2019a). An old approach to education management often neglects library and scientific information while the new modern and digitalized approach requires to give more importance to the development of a smart digital library.

\subsubsection{Innovation of education management from "non-digit" to digitalized educational management}

The increase in the status and role of a digital library - a smart school library depends on solutions creating favorable conditions for the development of digital libraries in the school. Some authors mention five conditions for the development of a DL. They are: (i) Ideas of synchronized library from the resources to the services organization of the library; (ii) Information infrastructure with hardwares like server, big data saving system; (iii) Internet transmit line; (iv) System of information processing and exploiting soft wares; (v) Data resource sources (Tran Thi Hong Nhien \& Le Manh Ha, 2018). Other authors emphasize six following conditions: (i) Appropriate investment policies for library development, (ii) Appropriate selection of technology, (iii) Development of qualified human resource for libraries, (iv) Priority to the development of electronic data resources together with solutions of digitalization and building up a set of digit volume in the library, (v) Renovating the way of organizing, introducing and advertising information services of libraries to readers and , (vi) Development of legal corridor typical for Big Data (Truong Thi Hong Quyen \& Pham Thi Thu, 2018). 
The above mentioned conditions for the development of the digital library are probably relevant to the practical changes of libraries from the traditional to the modern ones in general and, in particular, from libraries under the subsidized bureaucratic management system to an economic market mechanism in Vietnam. However, radical and comprehensive renovation of education and training firstly requires the change in the ideology of education management in the direction of digitalization with the special role of library in a smart school. The core idea here is to "return libraries back to schools". A smart school library must be "the library of the school and for the school". The typical feature of this library is to study and develop digitalized communication technologies to assist school's activities in order to develop creative outputs including creative qualifications and abilities of the learners.

Basing on the case study of a smart school library, some directions may be proposed in the renovation of educational management from "nondigit" to a digitalized one with a concrete case of digitalized university education. First, renovating education input management in the direction of digitalizing. The inputs of education management especially the university governance should be given more importance, for instance, "recruitment" for universities. The system of digitalized knowledge should be developed to help university governance know the admission progress well enough in order to answer necessary questions such as: How many percents of the population with university education need can be accessed and developed?; How many percents of candidates can access and be attracted to the admission information especially the information of admission consultation? How and to what extent the admission information can be updated? A basic question is how a smart, digital library can help a university in administrating its admission to ensure sustainable access and development of admission market? Secondly, the renovating the management process in the direction of digitalization in the sense of applying digital technology in teaching and learning and at the same time mobilizing smart library and digital knowledge in the whole education process. The question raised here is, e.g. how many percents of the learners accessing full, precise and at right time the information about the objective, contents of the education programs of a discipline, class and module can a digital library and DK ensure? How many percents of the learners accessing how much of necessary data resources for their study and research? How many percent of the learners can be via-internet connected with each other and to their teachers, researchers and other related people by learning duty in the university? An old education management system is limited in a class, a discipline, a module, while a digitalized one may widen "here and now" learning-asking and researching correlated networks among themselves with their teachers and others. Third, renovating output management of education in the digitalization direction. The question is that can a smart digital library with digitalised knowledge help the school to access and master the information of the labor market, employment of the school, namely the situation of employment of the graduates? A new issue of the output management of education in the digital direction is to seek the ways to support in the manner of "guaranteeing" the knowledge, abilities, skills the school develop for its learners. Fourth, the renovating scientific research management in the digitalization direction to educate and serve the community. Educational management in the old manner mainly concerns with educating and learning activities of the learners but neglects research activities of both learners and teachers. A smart school management give the first priority to the Research \& Development (R\& D), Research \& Innovation (R\&I,) linking to the education, training and serving the community for the sustainable development. A radical question raised here is how to digitalize all scientific research works of the school for the immediated access of teachers, learners and other staffs in the school. Some universities have been successful in building up a strong research team. However, another issue is what to do to create a system of scientific, technological network in the university where strong research teams form clues to connect and correlate "here and now" with the members and stakeholders inside and outside the university.

\section{DISCUSSION AND CONCLUSION}

In conclusion, digitalized educational management provides a renovation tendency of educational management in the context of a market economy, global integration and the 4.0 revolution. The smart school digital library is a library of a school that gives more importance to the R\&D and modern communication means, especially information and knowledge digitalizing technology in all of its activities. Digitalized education management considers a smart school digital library as both a subject and the mean to develop the qualifications and ability to create and innovate in their learners and provide smart products for the human and social inclusive and sustainable development.

\section{REFERENCES}

Balyer, A., \& Öz, Ö. (2018). Academicians' views on digital transformation in education. International Online Journal of Education and Teaching (IOJET), 5(4), 809-830. 
Berners-Lee, T., Hendler, J., \& Lassila, O. (2001). The Semantic Web. Scientific American, 284(5).

Bond, B., Marín, V.I., Dolch, D., Bedenlier, S., \& Zawacki-Richter, O. (2018). Digital transformation in German higher education: student and teacher perceptions and usage of digital media. International Journal of Educational Technology in Higher Education, 15:48.

Borgman, C. L. (1999). What are digital libraries? Competing visions. Information Processing \& Management, 35(3), 227-243.

Borgman, C. L. (2000). From Gutenberg to the Global Information Infrastructure: Access to information in the networked world. Cambridge, MA: MIT Press.

Cerna, L. (2014). Innovation, governance and reform in education. CERI Conference background paper, 3-5.

Dang Thanh Son (2018). Web Scale Discovery - WSD in university library website - The choice for smart library model, in Vietnam National University Hanoi - The Information - Library Center (2018). Ibid.

European Commission/EACEA/Eurydice (2019). Digital Education at School in Europe. Eurydice Report. Luxembourg: Publications Office of the European Union.

Joseph S. Nye, Jr (2016). The future of power. Information and Communication Press (in Vietnamese).

Kieu Thuy Nga \& Le Duc Thang (2018). Artificial Intelligence and the application potential in library activity. In Vietnam National University Hanoi - The Information - Library Center (2018). Ibid.

Le Manh Ha \& Tran Hong Nhien (2018). The tendency of library development in a modern society. In Vietnam National University Hanoi - The Information - Library Center (2018). Ibid.

Le Ngoc Hung \& Bui Thi Phuong (2019). The position and role of digitalized library in the renovation of university governance in corporatization tendency in Vietnam. In Vietnam National University Hanoi - The Information Library Center. The optimization of digital knowledge: Government - Enterprise - Library. Vietnam National University Press, 187-206.

Le Ngoc Hung (2015). System, Structure \& Social Differentiation. Vietnam National University Press.

Le Ngoc Hung (2019a). Management of digital education: The case study of smart university school. The proceeding of the first conference on teacher training innovation: 20 years of cross training of teachers. Vietnam National University Hanoi Press.

Le Ngoc Hung (2019b). The renovation of university governance in Vietnam: system theory and construction of modern professional model. Political Theory Journal, 3, 46-52.

Nguyen Huu Gioi (2018). Discussion of smart library in Industrial Revolution 4.0. In Vietnam National University Hanoi - The Information - Library Center (2018). Ibid.

OECD (2016). Innovating Education and Educating for Innovation: The Power of Digital Technologies and Skills. OECD Publishing, Paris.

Omidinia, S., Masrom, M., Selamat, H. (2012). Determinants of smart school system success: a case study of Malaysia. International Journal of Academic Research, 4(1).

Peter Drucker (1995). Capitalist society. Central Economic Management Institute. Hanoi, Vietnam (in Vietnamese).

Tran Thi Hong Nhien \& Le Manh Ha (2018). Selective distribution of information under the impact of Industrial Revolution 4.0. In Vietnam National University Hanoi - The Information - Library Center (2018). Ibid.

Tran Thi Thanh Nga \& Tran Thi Anh Van (2018). Digital resource software (BookWorm) - utility service for smart library. In Vietnam National University Hanoi - The Information - Library Center (2018). Ibid.

Truong Thi Hong Quyen \& Pham Thi Thu (2018). The impact of Big Data on the activity of The Information Library Center of Vietnam National University Hanoi. In Vietnam National University Hanoi - The Information - Library Center (2018). Ibid.

Vietnam National University Hanoi - The Information - Library Center (2018). Smart library 4.0: Technology - Data - Men. Vietnam National University Press.

Vo Dinh Hieu \& Le Ba Lam (2018). DoIT - The duplication document check for improving the quality of learning and research materials for universities in Vietnam. In Vietnam National University Hanoi - The Information Library Center (2018). Ibid.

Vu Thi Kim Anh \& Pham Thanh Quang (2018). RFID technology in library - Preconditions for self service. In Vietnam National University Hanoi - The Information - Library Center (2018). Ibid.

Zhu, Zhi-Ting, Yu, Ming-Hua \& Zhu, Peter Riezebos (2016). A research framework of smart education. Smart Learning Environments, 3:4. 